\title{
Persiguiendo al macho. Análisis cualitativo de los córpora
}

Palabras clave: macho - estereotipo lingüístico - México - corpus.

El objetivo de este artículo es reconstruir el estereotipo lingüístico del macho en la variante mexicana del español a partir del análisis cualitativo de los córpora. En el trabajo se analizarán las siguientes bases de datos: Corpus del Proyecto para el estudio sociolingüístico del español de España y de América PRESEEA, Corpus de las Sexualidades de México, Corpus Histórico del Español en México, Corpus del Español Mexicano Contemporáneo CEMC, Corpus de Referencia del Español Actual de la Real Academia Española CREA y Corpus de Español del Siglo XXI CORPES XXI.

\section{El estereotipo lingüístico}

El término llegó al campo de estudios de la lengua a través de la sociología, en particular de las obras de Walter Lipmann (1922), quien definió el estereotipo como "una imagen en la cabeza humana", una imagen unilateral, parcial y esquemática de un fenómeno y al mismo tiempo una opinión sobre aquel ${ }^{1}$. Para Hilary Putnam, la autora que más influencia ha tenido en la semántica general, el estereotipo es parte del conocimiento del mundo, "una parte muy convencional, cercana a la percepción cotidiana de la esencia de

${ }^{1}$ J. Bartmiński, Stereotypy mieszkają wjęzyku. Studia etnolingwistyczne, Lublin, Wydawnictwo UMCS, 2009, p. 55. Todas las traducciones del polaco son de la autora. 
objetos, fenómenos, etcétera"2. Es una idea de "qué apariencia tiene un X, cómo actúa, cómo es"3.

La autora del primer estudio lingüístico sobre los estereotipos, Uta Quasthoff, precisa:

El estereotipo es una expresión verbal de la creencia sobre un grupo social o un individuo miembro de tal grupo. Tiene forma de opinión lógica, no verificable, que tiende a valorar a base de emociones, adjudica unas cualidades o comportamientos a una clase de personas, o tal vez niega que esta clase tenga alguna cualidad. En la lingüística se puede describir como un enunciado ${ }^{4}$.

Sin embargo, no existen criterios inequívocos para identificarlo en datos lingüísticos. Al respecto, Telus sentencia:

A pesar de que Uta Quasthoff introduce tipologías de estereotipos en función de la cercanía o distancia a la superficie del enunciado que contiene o implica un estereotipo [...] (Quasthoff 1973:239), de la misma manera no propone un modelo de reconstrucción de la forma básica a base del enunciado ${ }^{5}$.

Según Adam Schaff, el contenido del estereotipo depende de "una palabra-denominación que causa una reacción emocional que se manifiesta en apreciaciones y actitudes de un individuo y que se pueden repetir casi automáticamente en relación a todos los ejemplares de cuyo nombre es esta palabra" 6 .

En la lingüística, los estudios sobre estereotipos tienen al menos dos direcciones: una se concentra en las relaciones de palabras que se reproducen mentalmente, y otra que estudia la parte profunda del estereotipo, es decir, juicios particulares sobre partes de realidad arraigados en la consciencia de los hablantes. La segunda corriente se divide en la orientación psicológica y la etnocognitiva ${ }^{7}$. El presente trabajo sigue los pasos de la escuela etnocognitiva de Lublin, según la cual,

la lengua que inevitablemente transmite ciertos estereotipos [...] construye una comunidad de pensamiento y percepción, y luego también influye en nuestros comportamientos. [...] La lengua funciona tanto como un "organizador" de la cultura, como su "espejo" y un archivo, un medio que perpetua la memoria sobre lo que fue y transmite la tradición a las siguientes generaciones $^{8}$.

${ }^{2}$ R. Tokarski, "Biała brzoza, czarna ziemia, czyli o miejscu stereotypu w opisie języka", en: J. Bartmiński, J. Anusiewicz (eds.), Stereotyp jako przedmiot lingwistyki. Teoria, metodologia, analizy empiryczne, Wrocław, Towarzystwo Przyjaciół Polonistyki Wrocławskiej, 1998, p. 125.

3 J. Bartmiński, op. cit., p. 67.

${ }^{4}$ U. Quasthoff, "Etnocentryczne przetwarzanie informacji. Ambiwalencja funkcji stereotypów w komunikacji międzykulturowej”, en: J. Bartmiński, J. Anusiewicz (eds.), op. cit., p. 13.

${ }^{5}$ M. Telus, "Stereotyp grupowy a predykacja", en: ibidem, pp. 136-137.

6 J. Panasiuk, "O zmienności stereotypów", en: ibidem, p. 137.

7 W. Chlebda, "Stereotyp jako jedność języka, myślenia i działania”, en: ibidem, p. 32.

8 J. Bartmiński, op. cit., p. 25. 
La teoría principal de la Escuela Etnolingüística de Lublin es la de la Imagen Lingüística del Mundo, término que significa la interpretación de la realidad compuesta por un conjunto de juicios sobre el mundo. La interpretación tiene su lugar en la lengua y la reflejan "tanto las formas gramaticales, el léxico, los proverbios, como los juicios presupuestos, es decir, los implicados por las formas lingüísticas, al nivel del saber social, creencias, mitos y rituales" ". Por eso, en el trabajo de la reconstrucción de la Imagen Lingüística del Mundo de un término dado hay que analizar lo siguiente: las definiciones del lema en distintos diccionarios, sus derivados, diminutivos, vocativos, metáforas, modismos, etimología de la palabra, etcétera ${ }^{10}$. De igual importancia en la metodología de la Escuela de Lublin es el análisis de textos y encuestas ${ }^{11}$. Jerzy Bartmiński hace resaltar la importancia de los patrones de la cultura escondidos en lo que presuponemos, es decir, todo un conjunto de juicios sobre el mundo, todo lo que un hombre corriente presupondría, si fuera necesario, con la fórmula "sé que..."

\section{Metodología}

El presente artículo es la continuación de la reconstrucción del estereotipo del macho en la variante mexicana ${ }^{13}$. En la Imagen Lingüística del Mundo del macho reconstruida a base de los diccionarios y refraneros, destaca su primera cualidad, la valentía: "que es valiente, fuerte o tiene alguna de las características que tradicionalmente se atribuyen a los hombres: iyo soy muy macho, hijos de la chingada, una mujer muy macha!"14. La siguiente es la creencia en la superioridad del sexo masculino al femenino: "Hombre que considera al sexo masculino como naturalmente superior al femenino, exalta las características tradicionalmente atribuidas a los hombres y pretende imponerse y dominar a las mujeres o demostrar su fuerza, su virilidad, etc., ante ellas u otros hombres: macho mexicano"15. En las definiciones de los diccionarios, además de lo sexual, los atributos de macho significan la preponderancia, tanto en el mundo de los animales como de plantas ${ }^{16}$.

9 J. Bartmiński, Językowe podstawy obrazu świata, Lublin, Wydawnictwo UMCS, 2009, p. 12.

${ }^{10}$ Ibidem, p. 156.

11 Ibidem, p. 157.

12 J. Bartmiński, Stereotypy mieszkaja..., op. cit., p. 38.

${ }^{13}$ Los resultados de la reconstrucción de la ILM del macho en la variante mexicana basada en el análisis de diccionarios, proverbios y frases hechas fueron presentados en la conferencia Young Linguistis'Meeting en Poznań en noviembre de 2016.

14 J. Palomar de Miguel, Diccionario de México, México, Editorial Trillas, 2005, p. 792; L.F. Lara, Diccionario de español usual en México, México, El Colegio de México, 1996, p. 577.

15 L.F. Lara, op. cit., p. 577.

${ }^{16}$ Por las exigencias de publicación, en el presente artículo no es posible presentar todo el análisis de los diccionarios y refraneros, por eso, nos limitaremos a un resumen. Por la misma razón no mencionamos las diferencias entre el español peninsular y el mexicano. 
En cuanto a los proverbios y locuciones, el más conocido "a lo macho" significa "a lo hombre, con hombría, firmeza y decisión. Con absoluta certeza, con seguridad"17, así como "sin engaños ni mentiras, con valentía"18 y "promesa formal, compromiso que se cumplirá con hombría"19. La misma característica resulta de "ser alguien muy macho" 20 . Igual de positivo es "rajarse alguien como los meros machos" 21 . No obstante, una serie de refranes, especialmente los que se refieren al mulo, destacan otras características del macho: obcecación, tenacidad, sinrazón, capricho, testarudez, por ejemplo, "esta mula es mi macho" 22 ,"no apearse alguien de su macho"23; "parar a alguien el macho" 24 , "montarse alguien en su macho; bajarse de su macho" 25 . Por supuesto, algunos indican también la imposición de poder del macho, por ejemplo, "En comiendo yo y mi macho, que reviente mi muchacho"26.

El siguiente paso en la reconstrucción de la ILM del macho es el análisis de textos. El mayor problema es la elección de los mismos, especialmente, cuando no nos limitamos a un tipo de textos, por ejemplo, a la prensa. Por esta razón, tratamos los córpora como una selección de los textos representativos para un país o un tema (dependiendo del tipo de corpus). Para los fines de este artículo se analizaron diferentes córpora ${ }^{27}$. El lema buscado fue "macho", sin diferenciar adjetivo o sustantivo. Dado el objetivo de la investigación, esto es, la reconstrucción del estereotipo lingüístico, se examinaron los fragmentos de los textos (exportaciones) en los que aparece el lema buscado. A continuación, tras el análisis del contenido, intentamos buscar similitudes para agrupar los resultados. Finalmente, se agruparon los resultados según tres ejes: qué piensan los demás sobre el macho, qué piensa el macho sobre sí mismo, qué relaciones tiene con las mujeres y con otros hombres.

\footnotetext{
17 J. Palomar de Miguel, op. cit., p. 792.

18 L.F. Lara, op. cit., p. 577.

19 M. Velasco Valdés, Refranero popular mexicano, México, Costa Amic Editores, 1979, p. 17.

${ }^{20}$ Ser muy valiente, no tener miedo a nada. J. Palomar de Miguel, op. cit., p. 792.

21 "Es una paradoja, porque, según el vulgo, no es de hombres retractarse, aunque aquí el
} refranista dice lo contrario; la verdad es que en ciertos casos se requiere más valor para retractarse, de lo que se cree. Macho es, en México, el muy hombre, el valeroso", M. Velasco Valdés, op. cit., p. 142.

22 Ibidem, p. 73.

${ }^{23}$ Significa que el macho no cede ante la razón y el convencimiento.

24 Detener o interrumpir la acción del que procede de manera inconveniente o desacometida.

25 Tomar una actitud, una decisión, etc., sostenerla con terquedad o no abandonarla ni ante razones. L.F. Lara, op. cit., p. 577.

${ }^{26}$ E. Bautista Adame, Proverbios, refranes, adagios, aforismos y expresiones populares mexicanas, México, Editorial el Tucan de Virginia, 2003, p. 134. Dados los requisitos de publicación de este artículo, debemos omitir una serie de refranes y locuciones de igual importancia, tales como: "Este macho es mi mula, y aunque respingue", "macho calado", "te gusta el trote de macho, aunque te zangolotee", "me quieres hacer un hijo macho" y otros (E. Bautista Adame, op. cit., pp. 149, 199, 211, 315), además de "taparle el ojo al macho" y otros (M. Velasco Valdés, op. cit., pp. 103, 153).

${ }^{27}$ Los primeros resultados del análisis fueron presentados en el V Foro de Lingüística Hispánica: panorama de temas y métodos de investigación que se celebró en Lublin el 11-13 de mayo de 2017. 


\section{Persiguiendo al macho}

El estudio comienza con el análisis de los córpora mexicanos: Corpus de las Sexualidades en México, Corpus Histórico del Español en México, Corpus del Proyecto para el estudio sociolingüístico del español de España y de América (subcorpus para la ciudad mexicana de Monterrey) y el Corpus del Español Mexicano Contemporáneo.

El primer corpus da como resultado el imperativo "rompe con el papel de macho". El segundo, el Histórico, proporcionó cinco casos: cuatro en el nombre "chile macho" y uno en la locución "taparle el ojo al macho" (fingir, disimular, aparentar ${ }^{28}$ ). En el tercero, el sociolingüístico, "macho" aparece una vez, como fragmento de un apellido. El Corpus del Español Mexicano Contemporáneo da en total 31 casos de uso del lema "macho", trece se refieren a los hombres, el resto a los animales, plantas o plomería. De las trece concordancias, tres tenían la colocación "muy macho" y dos "a lo macho", por ejemplo, "A mí, a lo mero macho, hasta coraje me da. Pos qué voy a andar pendiejiando" 29 . De las restantes concordancias podemos sacar las siguientes conclusiones: el macho debe ser valiente porque "si es muy macho que se vaya a confesar $[\ldots]$ ". 30 , tiene que pagar por todo, reírse cuando muera: "En ningún momento voy a morir riendo. Esto es ser macho" 31 . Debe presumir, si hace falta, "mexicano a veces echa bala cuando le sale lo muy macho"32. El ejemplo de macho mexicano es Rodolfo Acosta, o Jorge Negrete, actores ${ }^{33}$.

Por supuesto, para poder sacar cualquier conclusión es necesario que el número de casos sea más significativo y que sea posible identificar patrones del uso. Una de las razones de tales resultados puede ser el tamaño de los córpora, por ejemplo, el CSMX cuenta con 396 documentos (en total, un millón y medio de palabras), mientras que el CEMC contiene 996 textos $^{34}$. Por eso, vamos a analizar los córpora de referencia: Corpus de Referencia del Español Actual y Corpus del Español del Siglo XXI. Ambos han sido elaborados por la Real Academia Española, ambos vastos (el primero con 160 millones de formas, el segundo 250 millones). El CREA se compone de textos producidos desde 1975 hasta 2004, mientras que el CORPES XXI contiene textos escritos después del 2001 hasta 2012. En ambos es posible analizar exclusivamente el subcorpus de los textos producidos en México.

${ }^{28}$ M. Velasco Valdés, op. cit., p. 153.

${ }^{29}$ O. Lewis, Antropología de la pobreza, 1969, en: CEMC.

30 Ibidem.

31 O. Lewis, Los hijos de Sánchez, 1967, en: CEMC.

32 Anónimo, Cinta 340-CCXXIV-A, 1964, en: CEMC

33 C. Monsiváis, Días de guardar, 1971, en: CEMC.

34 CEMC quedó formado por un conjunto de 996 "textos" escritos por autores mexicanos desde 1921 hasta 1974, así como por transcripciones de conversaciones grabadas procedentes de los materiales del Atlas lingüístico de México y de otros acervos lingüístico-etnográficos existentes en la biblioteca de El Colegio de México. Otros córpora (CSMX y Preseea) no revelan el número de documentos ni palabras que los constituyen. 
Los resultados del corpus CREA muestran que "macho" aparece 203 veces. Dado que este corpus no permite ver la frecuencia de la palabra, comparamos este resultado con otros términos: "hombre" - 7.210; "hembra" - 162. "Macho mexicano" aparece solamente 12 veces en 6 documentos. Por su parte, el corpus CORPES XXI tiene herramientas imprescindibles para medir la frecuencia. En todas las regiones hispanohablantes obtenemos la frecuencia absoluta del "macho" (sustantivo) de 4.470 (en 1848 documentos) y la frecuencia normalizada 18,07 casos por millón. Los resultados nos muestran un mayor uso de la palabra en España (1404 casos) que en México (502 casos), también la frecuencia normalizada demuestra mayor uso en España (5,67 casos por millón) que en México $(2,02)$. No obstante, hay que tener en cuenta la distribución geográfica de los textos recopilados para CORPES XXI. Como adjetivo, los resultados generales son los siguientes: 658 casos en 454 documentos. Con más frecuencia el adjetivo "macho" aparece en los documentos de España (175 casos), de México tenemos 134 casos. Contrariamente a lo escrito arriba, en México la frecuencia normalizada es de 4,95 casos por millón, mientras que en los textos de España 2,06 casos por millón (con la frecuencia normalizada promedia de 2,66).

\section{Resultados del análisis cualitativo}

De los 502 casos de uso de "macho" como sustantivo (también plural) obtenidos en el CORPES XXI, tenemos que descartar los que se refieren a los animales, plantas (plátano macho), partes del vestuario del matador, además de la expresión "taparle el ojo al macho". Quedan 255 ocurrencias por analizar. De las 134 concordancias del "macho" adjetivo, casi la mitad (66) se refiere a los hombres, el resto se refiere a plátanos, insectos, animales, etcétera. También debemos descartar expresiones tales como "taparle el ojo al macho", "a lo macho", "no suelta al macho", "cada quien con su macho" y "apretarse los machos". Por lo tanto, de los casos del CORPES XXI tenemos un total de 304 casos que serán objeto de nuestro análisis. En el CREA, de los 203 casos del lema "macho", solamente 89 se refieren al hombre, mientras que, del lema "machos", de los 81 quedan 33 por analizar. A continuación se analizaron párrafos (en caso del CREA) y exportaciones (CORPES XXI), tal como se analiza el texto con el fin de reconstruir un estereotipo lingüístico.

Los resultados del análisis los agrupamos según los actores: el macho en los ojos de los demás, el macho sobre él mismo, en relación a las mujeres y en relación a otros hombres. En la primera parte reconstruiremos las expectativas sociales sobre el aspecto físico del macho, su comportamiento. En la segunda, cómo un hombre se reconoce como macho. Y en la tercera, como deberían ser sus relaciones con las mujeres y con otros hombres.

Empezamos por el aspecto físico del macho: ¿cómo es ante los ojos de los demás? A partir de los fragmentos de texto analizados, podemos dibujar 
la imagen de un hombre alto, robusto, "hombre de pelo en pecho", bigote que huele mal, bebe tequila ("whisky de los machos"), borracho, violento, vulgar: "por tres cosas se conoce a los hombres cabales: por la manera de beber tequila, de mirar a las mujeres y de agarrar el taco" "35. Pedro Infante fue una encarnación del macho: fuerte y voluntarioso. A pesar de que el macho es una figura respetable y con poder, que tiene un orgullo exagerado de ser macho ("es puro coraje de macho") encontramos también usos ofensivos, tales como "macho de mierda"; "pendejo macho".

La siguiente pregunta del análisis es ¿qué es lo que se espera de él? Lo fundamental es que el macho no llora, este verbo aparece siete veces. Cinco veces tenemos el verbo aguantar(se): "A ver si sigues tan machito. A ver cuánto aguantas" ${ }^{36}$. El macho no se queja, sonríe frente a la muerte, y algo muy mexicano: no se raja: "Ya estaría que yo me rajara a la mera hora de demostrar quién soy y de dónde rechingados vengo. Soy macho y no le saco ni una vara a los chingamadrazos" 37 . Otros verbos que indican el comportamiento propio del macho son los siguientes: vencer, chingar, avasallar, someter, pelear, enfrentarse, embestirse, retar. En resumen, el macho tiene que demostrarlo: "Lo malo de ser macho y querer demostrarlo es no tener la ocasión"38.

Uno no nace macho, sino se hace, como en este fragmento: "Te odias por estar aquí, por haber salido al mundo sin salvavidas. Por hacerte el machito y presentarte en la perrera sin vacuna para la rabia" ${ }^{39}$. El hombre se siente muy macho ("Yo me sentía muy macho, pero la vieja me desarmaba"40), y cuando no se siente, lo pretende, actúa ("Felipe resolvía subir al escenario y actuar el papel del macho que goza de empuñar una pistola cargada"41). Lo que es evidente es que "le da gusto ser macho" 42 , porque "tiene su encanto" 43 . El orgullo del macho implica el orgullo por la patria: "Yo soy mexicano, mi tierra es bravía, palabra de macho que no hay otra tierra más linda y más brava" 44 . De ahí viene el deber de defender a los suyos. El poder que tiene el macho significa que "él manda y no se equivoca, si se equivoca vuelve a mandar. Presume de una preparación y capacidad intelectual muy grande, por eso

35 J.A. Quijano, Pedro Infante era un macho muy especial, eluniversal.com.mx, 2007-04-15, en: CORPES XXI.

${ }^{36}$ E. Álvarez Estrada, Te prometo, encadenado o El corrido del sobrino desobediente (Narcotragicomedia en un acto), dramared.com, 2007, en: CORPES XXI.

37 J. Muñoz Vargas, Juegos de amor y malquerencia: novela, México D. F., Joaquín Mortiz, 2003, en: CREA.

38 Ibidem.

39 J. Hurtado, Crónica sero, Monterrey, Consejo para la Cultura y las Artes de Nuevo León, 2003, en: CREA.

${ }^{40}$ P.A. Palou, Con la muerte en los puños, México D. F., Alfaguara, 2003, en: CREA.

41 J. Montelongo, Quincalla, México, Jus, 2004, en: CORPES XXI.

42 D. Serrano, El carbón en la boca de Porcia, dramared.com, 2012-12-01, en: CORPES XXI.

43 J.A. Quijano, Alex Mercader, un macho muy 'padrino', eluniversal.com.mx, 2006-02-22, en: CORPES XXI.

${ }^{44}$ C. Fuentes, Cristóbal Nonato, en: CREA. 
opina sobre cualquier problema y se considera capaz de desempeñar cualquier cargo público o privado" 45 .

Sorprendentemente, no lee poesía, ni libros: "A tu abuelo nunca le gustó que tu padre leyera poesía. Cosas de machos"46. De los verbos que aparecen solo una vez tenemos una imagen negativa del hombre que se menosprecia, sabe sus defectos; no entiende razones, no presta ayuda, protesta cuando ve afectados sus intereses, no se une a otros, debe ser diferente, se viste en forma de hacerse notar, oculta sus errores, usa la mentira y la falsedad, engaña.

Vamos a examinar las relaciones del macho con las mujeres. Primero, hace una división clara entre las mujeres "de casa" y las demás. A las primeras el macho las defiende. "¿Que si lo volvería a hacer? Pos por mi madre sí, para eso soy muy macho, pero si me encierran, ¿quién la va a defender, verdá? ¿Pos quién?" 47 Les presta atención, es su proveedor y espera que su mujer se quede en casa. La principal obligación del macho respecto a las mujeres es fecundar: "ióyeme macho mexicano, embaraza a tu señora, pero ya!"48 Debe tener un hijo varón, primogénito, digno heredero: "Yo tuve un machito y nació muerto. La comadrona, que era saurina, me previno: Si esto llega a oídos de tu señor, te mata; lo bueno es que está en el rancho" 49 . La relación entre el macho y su hijo es especial: "un amor puro y animal: el del macho por su progenie, de un hombre mayor por su hijito hermoso" ". No obstante, este deber de fecundar no se refiere solamente a la mujer "de casa", sino a tantas mujeres como sea posible. Debe tener muchos retoños: "Tu papá es un macho y los dos creyeron que en la Biblia dice que las mujeres no podemos cuidarnos y debemos darles a los machos todos los niños que quieran" ${ }^{2}$. No obstante, no le importa si es capaz de mantenerlos, niega a la familia lo necesario para su subsistencia: "Dice Santiago que su padre era un macho testarudo que quería tener diez hijos, pero que no pensaba en que comerían mal y vestirían peor" 52 .

La diferenciación de las mujeres se muestra también en la forma de trato. A las segundas las desprecia: "Los mingitorios son como las mujeres, los usas y ya - respondió Carlos antes de soltar una carcajada pero, entonces, agregó- Ojo: eso no lo dije yo. Lo dijo Matatías, ese macho que me sale a veces y que todo hombre que se precie lleva dentro" 53 . Les da miedo: "le daba lecciones de cómo ser bien macho y tratar mal a las viejas para que se

45 J. Matute Vidal, I. Matuite Ruiz de Vázquez, Perfil del mexicano, en: CREA.

46 M.A. Hernández Acosta, Hijo de hombre, México D. F., Jus, 2011, en: CORPES XXI.

${ }^{47}$ M. Cervantes, "Pos quién". Caminos sin historia, Guadalajara, Ediciones Euterpe, 2006, en: CORPES XXI.

${ }^{48}$ C. Fuentes, op. cit., en: CREA.

49 F. Ruiz, Telares, México D. F., Ediciones Era, CONACULTA-INBA, 2002, en: CORPES XXI.

50 D. Ojeda, La santa de San Luis, México D. F., Tusquets Editores, 2006, en: CORPES XXI.

51 A. Páez Varela, El reino de las moscas, México D. F., Alfaguara, 2012, en: CORPES XXI.

52 S. Molina, En silencio, la lluvia, México, Alfaguara, 2008, en: CORPES XXI.

53 A. Clavel, Cuerpo náufrago, México D. F., Alfaguara, 2005, en: CORPES XXI. 
dieran cuenta de-quién-es-el-que-manda" ${ }^{54}$. Es golpeador, violento, insensible, bruto, las domina, maltrata, viola, chinga para demostrar su hombría. Al mismo tiempo ellas son objetos sexuales, trofeos. El macho exhibe su capacidad para conquistar, hace gala de su capacidad amatoria, es cazador de las mujeres, las conquista, seduce: "La había seducido por ego, por ganar, sí... le chocaba la palabra, pero ipor macho! [...] todo por su fama de difícil, por eso le había echado el ojo, por considerarla un trofeo" 55 . La obligación de tener sexo con muchas mujeres significa que el macho nunca le niega sexo a una mujer, si ella quiere: "¿qué quieres que yo haga si ellas se me ofrecen? ¿Que deje de ser hombre? ¿Que me pierdan el respeto?"56

El trato entre el macho y las otras mujeres está marcado por la atracción sexual, también por parte de las mujeres. El macho es atractivo porque es macho: "Los feos tienen su atractivo cuando son muy machos, [...] Son para que te sacudan contra el suelo"57; "¡Ay, cariñito! Por eso me gustas: no por sumiso sino por macho, aunque ni te enteres" $" 58$. En estas relaciones las mujeres no se quedan indefensas, los pueden manipular, porque el mayor miedo del macho es dejarlas insatisfechas: "Así que aprendí a fingir, iy cómo les gusta a los hombres que sus hembras les finjan! Aunque digan que no, eso los hace sentir tan viriles, tan machos, mucho mejor que enfrentar que sus mujeres no sintieron nada"59. Otro recurso de las mujeres es el abandono, no obstante, el macho herido, ofendido, debe mantener su orgullo, no debe agacharse ante una hembra, debe vengarse.

En las relaciones con otros hombres la figura más significativa es la del homosexual, la negativa del macho. "Más fuerte, ¿o qué, eres un maricón? Dame, macho"60; "El Hombre: ¡Qué puto!, ¿quieres ver...? Soy bien machito" $"$. Y tal como uno se hace macho, a un homosexual se lo puede convertir en un macho: "sin embargo, su comportamiento se modifica radicalmente por la influencia de su padre y de una mujer, quienes para el honor y la unión de la familia consiguen convertirlo en un verdadero macho y llevarlo por el buen camino, ya que contrae matrimonio - y por la Iglesia - con una mujer" ${ }^{\prime 62}$. No obstante, la relación entre hombres hetero y homosexuales es más compleja a causa de la figura del "macho calado". La homosexualidad pasiva es lo que causa repulsión ("iQué miedo! ¿Qué?, ¿dejas que te la meta? O ¿eres macho calado?"63). Las experiencias homoeróticas no tanto

${ }^{54}$ W. Bruciaga, Funerales de hombres raros, México D. F., Jus, 2011, en: CORPES XXI.

55 J. Hayen, Por la calle de los anhelos, en: CREA.

${ }^{56}$ E. González, Quién como Dio, en: CREA.

${ }^{57}$ L. González de Alba, Otros días, otros años, México D. F., Planeta, 2008, en: CREA.

58 N. Alvarado, “¡Oh, diosas!”, en: L. Cuéllar et al., Ellas... por ellos, México D. F., Consejo Nacional para Prevenir la Discriminación, 2012, en: CORPES XXI.

${ }_{59}$ M. Carrillo, Ni santa ni golfa, México D. F., Diana, 2009, en: CORPES XXI.

${ }^{60}$ P.A. Palou, op. cit., en: CORPES XXI.

${ }^{61}$ H.A. Hinojosa, Desiertos, México D.F., Tierra Adentro, 2007, en: CORPES XXI.

62 A. Díaz Mendiburo, Los hijos homoeróticos de Jaime Humberto Hermosillo, México D. F., Plaza y Valdés, 2004, en: CORPES XXI.

${ }^{63}$ H.A. Hinojosa, op. cit., en: CORPES XXI. 
("Bueno, pues ya eres un macho probado, ¿no? Malo que te hubiera gustado y yo tuviera que escaparme de ti, putito"64), especialmente cuando se trata de los machos: "Cuando era adolescente, a cada rato escuchaba decir a los hombres de mi barrio que el único macho verdadero era el macho calado" 65 .

\section{Conclusiones finales}

El objetivo inicial de este trabajo fue reconstruir el estereotipo lingüístico del macho en el español de México a base de los córpora. A pesar de que, según los grandes pensadores mexicanos Octavio Paz o Samuel Ramos, la figura del macho juega un papel principal en la formación de la identidad mexicana ${ }^{66}$, sorprendentemente, la mayor dificultad ha sido la escasez de datos. No obstante, el estereotipo reconstruido cumple con los requisitos del estereotipo lingüístico formulados por Uta Quasthoff: es una expresión verbal de la creencia sobre un grupo social (machos) o miembro de tal grupo (macho); tiene la forma de opinión lógica, no verificable, valora a base de emociones, les adjudica a los machos/macho unas cualidades y comportamientos y también les niega otras cualidades ${ }^{67}$. De esta manera obtenemos el siguiente enunciado: el macho es un hombre violento, orgulloso, que debe ocultar sus sentimientos, que ama a su madre y su esposa, despreciando a las demás mujeres, que quiere tener muchos hijos aunque no se preocupa por su bienestar, que desprecia a los homosexuales al mismo tiempo que tiene sexo con ellos.

Debemos tener en cuenta la dificultad del método utilizado en el presente artículo, conforme a lo escrito por Aleksy Awdiejew:

Suponemos la existencia de un área organizada de estereotipos que constituye una base cognitiva que permite interpretar el texto. El texto en este marco se entiende como una representación incompleta del contenido para transmitir. Identificar las fronteras y la profundidad de la base cognitiva para entender un texto dado es, en mi opinión, la tarea metodológica más difícil ${ }^{68}$.

De ahí, este estereotipo no está completo, pero seguramente nos acerca a los patrones culturales que rigen la tradición mexicana.

${ }^{64}$ P.A. Palou, op. cit., en: CORPES XXI.

65 J. Herbert, Canción de tumba, Barcelona, Mondadori, 2011, en: CORPES XXI.

66 S. Ramos, El perfil del hombre y la cultura en México, México, Editorial Pedro Robredo, 1938. O. Paz, El laberinto de la soledad, México, Fondo de Cultura Económica, 1993 (1975).

${ }^{67}$ U. Quasthoff, op. cit., p. 13.

68 A. Awdiejew, "Standardy semantyczne a znaczenie leksykalne", en: J. Bartmiński, J. Anusiewicz (eds.), op. cit., p. 57. 


\section{Referencias bibliográficas}

AWDIEJEW Aleksy

1998 "Standardy semantyczne a znaczenie leksykalne”, en: Bartmiński J., Anusiewicz J. (eds.), Stereotyp jako przedmiot lingwistyki. Teoria, metodologia, analizy empiryczne, Wrocław, Towarzystwo Przyjaciół Polonistyki Wrocławskiej, pp. 53-62.

APPENDINI Guadalupe

1999 Refranes y aforismos mexicanos, México, Editorial Porrúa.

BARTMIŃSKI Jerzy

2009a Stereotypy mieszkaja w języku. Studia entolingwistyczne. Lublin, Wydawnictwo UMCS.

2009b Językowe podstawy obrazu świata. Lublin, Wydawnictwo UMCS.

BAUTISTA ADAME Enrique

2003 Proverbios, refranes, adagios, aforismos y expresiones populares mexicanas, México, Editorial el Tucan de Virginia.

CHLEBDA Wojciech

1998 "Stereotyp jako jedność języka, myślenia i działania”, en: Bartmiński J., Anusiewicz J. (eds.), Stereotyp jako przedmiot lingwistyki. Teoria, metodologia, analizy empiryczne, Wrocław, Towarzystwo Przyjaciół Polonistyki Wrocławskiej, pp. 31-41.

GRZEGORCZYKOWA Renata

1998 "O rozumieniu prototypu i stereotypu we współczesnych teoriach semantycznych", en: Bartmiński J., Anusiewicz J. (eds.), Stereotyp jako przedmiot lingwistyki. Teoria, metodologia, analizy empiryczne, Wrocław, Towarzystwo Przyjaciół Polonistyki Wrocławskiej, pp. 109-115

LARA Luis Fernando

1996 Diccionario de español usual en México, México, El Colegio de México.

PANASIUK Jolanta

1998 “O zmienności stereotypów”, en: Bartmiński J., Anusiewicz J. (eds.), Stereotyp jako przedmiot lingwistyki. Teoria, metodologia, analizy empiryczne, Wrocław, Towarzystwo Przyjaciół Polonistyki Wrocławskiej, pp. 84-98.

PALOMAR DE MIGUEL Juan

2005 Diccionario de México, México, Editorial Trillas.

PAZ Octavio

1993 El laberinto de la soledad, México, Fondo de Cultura Económica.

PEREZ MARTINEZ Herón

2004 Refranero mexicano, México, Fondo de Cultura Económica.

QUASTHOFF Uta

1998 "Etnocentryczne przetwarzanie informacji. Ambiwalencja funkcji stereotypów w komunikacji międzykulturowej”, en: Bartmiński J., Anusiewicz J. (eds.), Stereotyp jako przedmiot lingwistyki. Teoria, metodologia, analizy empiryczne, Wrocław, Towarzystwo Przyjaciół Polonistyki Wrocławskiej, pp. 11-30.

RAMOS Samuel

1938 El perfil del hombre y la cultura en México, México, Editorial Pedro Robredo.

TELUS Magdalena

1998 "Stereotyp grupowy a predykacja”, en: Bartmiński J., Anusiewicz J. (eds.), Stereotyp jako przedmiot lingwistyki. Teoria, metodologia, analizy empiryczne, Wrocław, Towarzystwo Przyjaciół Polonistyki Wrocławskiej, pp. 135-145.

TOKARSKI Ryszard

1998 "Biała brzoza, czarna ziemia, czyli o miejscu stereotypu w opisie języka" en: Bartmiński J., Anusiewicz J. (eds.), Stereotyp jako przedmiot lingwistyki. Teoria, metodologia, analizy empiryczne, Wrocław, Towarzystwo Przyjaciół Polonistyki Wrocławskiej, pp. 124-134. 
VELASCO VALDÉS Miguel

1979 Refranero popular mexicano, México, Costa Amic Editores.

\section{Bancos de datos}

PRESEEA

2014 Corpus del Proyecto para el estudio sociolingüistico del español de España y de América, Alcalá de Henares, Universidad de Alcalá, <http://preseea.linguas.net>, 3.03.2017.

REAL ACADEMIA ESPAÑOLA

CREA. Banco de datos Corpus de referencia del español actual, <http://www.rae.es>, 10.04.2017.

CORPES XXI. Banco de datos Corpus de Español del Siglo XXI, <http://web.frl.es/CORPES/ view/inicioExterno.view>, 20.04.2017.

UNIVERSIDAD NACIONAL AUTÓNOMA DE MÉXICO

Corpus de las Sexualidades en México (CSMX), <http://www.corpus.unam.mx/csmx>, 3.03.2017.

Corpus Histórico del Español en México (CHEM), <http://www.corpus.unam.mx/chem>, 3.03.2017.

Diccionario del Español de México. Corpus del Español Mexicano Contemporáneo (CEMC). $<$ http://www.corpus.unam.mx/cemc>, 4.03.2017.

\section{Chasing the macho. Qualitative analysis of corpora}

Keywords: macho - linguistic stereotype - Mexico - corpus.

\section{Abstract}

The main purpose of this article is to reconstruct the linguistic stereotype of the macho in the Mexican Spanish. The applied methodology is a qualitative analysis of various corpora: Corpus del Proyecto para el estudio sociolingüístico del español de España y de América PRESEEA, Corpus de las Sexualidades de México, Corpus Histórico del Español en México, Corpus del Español Mexicano Contemporáneo CEMC, Corpus de Referencia del Español Actual de la Real Academia Española CREA and Corpus de Español del Siglo XXI CORPES XXI. As a result, we have a description of how the macho should look like, behave, treat women and other men. However, the results prove also that the word "macho" is rarely used by the Mexicans and this conclusion requires further investigation.

Fecha de recepción: 24.02.2018

Fecha de aceptación: 16.04.2018 